\title{
Assessing the Effect of Waiting Times on Restaurant Service Delivery in the Ho Municipality, Ghana
}

\author{
Lolonyo Letsa \\ Department of Hospitality and Tourism Management, Ho Technical University, Ho, Ghana
}

\section{Email address:}

lonawud@yahoo.com

\section{To cite this article:}

Lolonyo Letsa. Assessing the Effect of Waiting Times on Restaurant Service Delivery in the Ho Municipality, Ghana. European Business \& Management. Vol. 3, No. 6, 2017, pp. 113-119. doi: 10.11648/j.ebm.20170306.13

Received: February 6, 2017; Accepted: June 15, 2017; Published: November 25, 2017

\begin{abstract}
This study seeks to establish the effect of waiting times on restaurant service delivery in the Ho Municipality, Ghana. Specifically, to assess the wait time experienced and expected by customers during four different periods of the customer's total time of engaging the restaurant services. A descriptive, cross-sectional survey was conducted among 50 purposively customers of restaurant services. Both descriptive and inferential statistics were computed during the analysis of the data using both SPSS and Microsoft Excel. Results show that the average waiting time under all the sub sections measured exceeds the average waiting time customers actually want to do. This is not good for customers as they want a cut down on the amount of time spent waiting from the period of entering the restaurant to the point of exiting. It is confidently concluded that customers are not satisfied with the long waiting times spent in the restaurant. This could affect total satisfaction of the customers. Also, server behaviors are good with the personality traits of the servers being ranked highest followed by the job related attributes. Request related attributes were the least ranked. It was thus, recommended that management and employees should work hard at reducing the waiting times at each level of the service process since customers are dissatisfied with the excessive waiting times. Most customers would prefer not spending more than five minutes at each stage of the service process hence management should seriously consider activities that will help reduce the waiting time. Furthermore, management should equally put in place some measures that will prevent customers from feeling bored during the period of waiting.
\end{abstract}

Keywords: Wait, Time, Restaurant, Service, Delivery

\section{Introduction}

According to [1] customers have become more sophisticated, value and price conscious, demanding and thus switch swiftly to other alternatives in case of a single dodgy experience. A study conducted by [2] indicated that waiting for service in the hospitality industry is a negative experience for many customers which ultimately affect the service provider directly when the waiting time is not managed well either by losing both customer and revenue. The quality of guests' experiences during unavoidable waiting times could be the essential factor that controls the success of the hospitality businesses or could be a major detriment. A long waiting time influences customers' dissatisfaction with the service provider, and can give customers a negative experience.

In the explanation of [3] waiting is often an unavoidable experience in many business settings. People usually wait in line when the demand for a service exceeds its supply [4]. In some instances, customers wait for few minutes, hours, days or months depending on the type of product and service ordered. In other words, waiting time could be related to inability to match demand with supply and this affect service delivery. Some researchers believe customers can tolerate waiting if it is presented well to make it fun and suggested that making waiting time more fun or tolerable will make customers become more patient [5], [6]. In their view, [5] indicated that attractiveness of the waiting environment is determined by its physical design, such as, comfort, space, and its aesthetic features. Those physical designs attract customers and will have influence on the affective aspect of waiting time. Furthermore, [7] assert that when customers perceive attractiveness of the waiting environment will have positive influence on the affective response during the 
waiting period. Nowadays, many companies use some ways to make customers have more patients, such as let customers sit in the bar and order something for them, or offer customers a cup of drink while they are waiting. However, when customer waiting time is too long, consumers still will feel dissatisfied. Service providers may lose one or several sale chances, and even worse, such as lose a loyal customer [5].

According to [8] acceptable waiting times are more identified in a multi-stage restaurant system. According to their study, acceptable waiting times vary depending on the stage in the service process or sequence (i.e. welcome, greet, seat, order, serve, check, and pay, farewell), and respondents' expectation levels (i.e. very satisfactory, satisfactory, unsatisfactory, very unsatisfactory). In their view, Guests could afford to wait longer in some stages, such as the seating stage and serving stage, but in some other stages, such ordering and paying, guests would not accept the long wait.

This study therefore seeks to establish the effect of waiting times on restaurant service delivery in the Ho Municipality, Ghana. Specifically, to assess the wait time experienced and expected by customers during four different periods of the customer's total time of engaging the restaurant services. These are; waiting time just after arrival at the restaurant, waiting time after receiving a menu, waiting time after placing an order and waiting time after completing a meal.

\section{Methodology}

This study used descriptive, cross-sectional study design. The setting was the Ho Municipality in Volta Region, Ghana. The population for this study included customers of catering services operators in the Ho Municipality. A total of 50 customers all in the Municipality were selected for the research. The study employed a purposive sampling technique in selecting the customers located in various parts of the Ho Township in Volta Region, Ghana.

Data for the study was obtained using questionnaire. The questionnaire consisted of demographic information such as gender, age, income, waiting times for restaurant services and behaviours that restaurant servers might engage in as they perform their jobs.

Both descriptive and inferential statistics were computed during the analysis of the data using both SPSS and Microsoft Excel. The descriptive aspect employed frequency tables; and pie chart whilst the inferential aspect of the analysis employed $\mathrm{t}$ - test to test if there is no significant difference between the expected and actual waiting time averages.

\section{Results and Discussions}

A total of 50 individual customers completed the questionnaire on the usage of mobile money payment system. Table 1 summarizes the socio-demographic information of the respondents.
Table 1. Demographic information of the participants $(n=50)$.

\begin{tabular}{lll}
\hline Variables & Frequency & Percentage \\
\hline Gender & 22 & \\
Male & 28 & 44.0 \\
Female & & 56.0 \\
Age & 9 & \\
Below 25 & 11 & 18.0 \\
$26-35$ & 19 & 22.0 \\
$36-45$ & 7 & 38.0 \\
$46-55$ & 4 & 14.0 \\
56 and above & & 8.0 \\
\hline
\end{tabular}

Source: Field Data, 2016

From the Table 1, 22 respondents which represent 44\% were males and 28 of them which represent $56 \%$ were female. The analysis further indicated that $18 \%$ were below the age of $25,22 \%$ were between 26 to $35,38 \%$ were between 36 to $45,14 \%$ were between 46 to 55 and finally, $8 \%$ of them were 56 years and above.

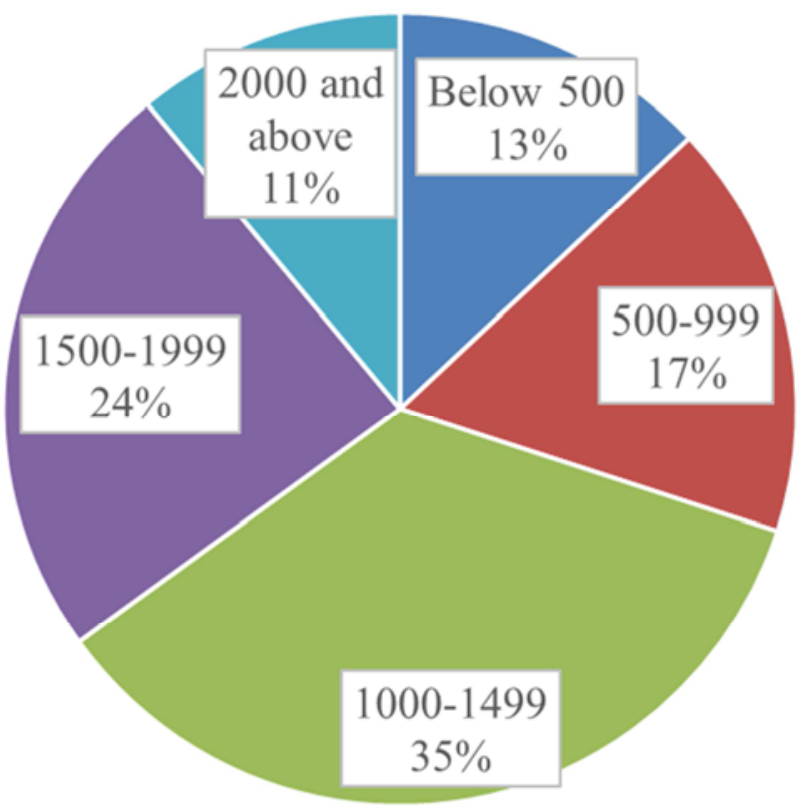

Figure 1. Proportion of Respondents by Income Level.

The above figure shows that $35 \%$ of the respondents belong to $\mathrm{GH} \not C 1000$ and $\mathrm{GH} \not C 1499$ income range group, $24 \%$ belong to between $\mathrm{GH} \not C 1500$ and $\mathrm{GH} \not \subset$ 1999; 17\% belong to between $\mathrm{GH} \not \subset 500$ and $\mathrm{GH} \not \mathbf{C} 999 ; 13 \%$ belong to

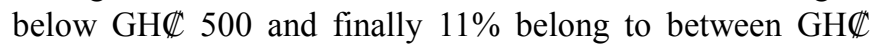
2000 and above.

Waiting time after arriving at the restaurant

This period deals with the time the guest arrives in the restaurant till the time the guest is given a menu card to place an order. The actual time experienced waiting and their perceived expected waiting times were obtained and analyzed and the results as follows; 
Table 2. Wait Time Experienced and Acceptable after Arriving at the Restaurant.

\begin{tabular}{lll}
\hline & Frequency & Percent \\
\hline Actual waiting time experienced & & \\
5 minutes or less & 22 & 44.9 \\
6-10 minutes & 20 & 40.8 \\
11-15 minutes & 5 & 10.2 \\
21-25 minutes & 2 & 4.1 \\
Expected waiting time & & \\
5 minutes or less & 37 & 74.7 \\
6-10 minutes & 7 & 14.9 \\
11-15 minutes & 2 & 4.3 \\
21-25 minutes & 1 & 2.1 \\
\hline
\end{tabular}

From the table above out of the 50 respondents, it appears that the distribution of respondents by wait time experienced after arriving at a restaurant is quite evenly spread between 5 minutes or less to 10 minutes. This implies that about $88 \%$ $(44.0 \%+40.0 \%)$ of the times, customers will have to wait for about 5 minutes or less to 10 minutes before being seated at a table. However, about $74 \%$ of the respondents further indicated they find it acceptable to wait for about 5 minutes or less before being seated at a table. Comparatively, it is observed that whilst customers expect to wait less than five minutes most of the times ( $74 \%$ of the time), they find themselves waiting less than five minutes only forty-four (44\%) percent of the time. We next examine the average wait time experienced and wait time expected and the two sample t-test was also performed to substantiate our observation.

Table 3 Comparing the Average Time Experienced and Wait Time Expected After Arriving at the Restaurant.

\begin{tabular}{lll}
\hline & $\begin{array}{l}\text { Wait time } \\
\text { experienced }\end{array}$ & $\begin{array}{l}\text { Wait time } \\
\text { expected }\end{array}$ \\
\hline Mean & 8.90 & 6.60 \\
Variance & 21.72 & 14.25 \\
Observations & 50.00 & 47.00 \\
Hypothesized Mean Difference & 0.00 & \\
df & 93.00 & \\
t Stat & 2.68 & \\
P(T<=t) one-tail & 0.00 & \\
t Critical one-tail & 1.66 & \\
\hline
\end{tabular}

Evidence from table 3 above provides us the evidence to refuse accepting the null hypothesis that there is no significant difference between the expected and actual waiting time averages. The P-Value of 0.00 for a one tailed distribution is less than 0.05 lending us the confidence to refuse accepting the null hypothesis at a 95\% level of confidence. The implication is that; customers wait for far too long than they actually expect to wait whenever they arrive at the restaurant before a menu card is given them. The t-stat and t-critical values also lend credence to this.

Waiting time after receiving a menu

Again, over here, the time duration between when a menu card was handed over to the customer to the point when the order was placed was obtained both for expected and actual waiting times. The results obtained are discussed in the tables that follow;
Table 4. Wait Time Experienced and Acceptable after Receiving a Menu.

\begin{tabular}{lll}
\hline & Frequency & Percent \\
\hline Wait time experienced & & \\
5 minutes or less & 23 & 46.9 \\
6-10 minutes & 16 & 32.7 \\
11-15 minutes & 7 & 14.3 \\
16-20 minutes & 2 & 4.1 \\
21-25 minutes & 1 & 2.0 \\
Acceptable time to wait & & \\
5 minutes or less & 24 & 51.1 \\
6-10 minutes & 22 & 46.8 \\
11-15 minutes & 1 & 2.1 \\
\hline
\end{tabular}

It appears from the table above that majority of the respondents which represent $46.9 \%+32.7 \%=79.6 \%$ indicated that they waited for about 5 minutes or less to 10 minutes after receiving a menu before a server returns to take their order. However, about $97.9 \%$ of the respondents further indicated they find it acceptable to wait between 5 minutes or less to 10 minutes after receiving a menu before a server returns to take their order.

Table 5. Comparing the Average Time Experienced and Wait Time Expected after Receiving a Menu.

\begin{tabular}{lll}
\hline & $\begin{array}{l}\text { Wait time } \\
\text { experienced }\end{array}$ & $\begin{array}{l}\text { Wait time } \\
\text { expected }\end{array}$ \\
\hline Mean & 9.12 & 7.55 \\
Variance & 23.82 & 7.47 \\
Observations & 50.00 & 47.00 \\
Hypothesized Mean Difference & 0.00 & \\
df & 78.00 & \\
t Stat & 1.97 & \\
P(T<=t) one-tail & 0.03 & \\
t Critical one-tail & 1.66 & \\
\hline
\end{tabular}

Again from the table 5, we support the argument that customer's actual and expected average waiting time after they were given a menu card vary. The P-Value again lends credence to this assertion with a value of 0.03 which is less than 0.05. This implies that we refuse to accept the null hypothesis that seek to suggest no difference in average expected and actual waiting times of customers after given a menu. It implies that there exists significant difference between the expected average waiting time of 7.55 and the actual experienced waiting time of 9.12 at the $95 \%$ confidence level.

Waiting time after placing an order

Information on expected and actual waiting time of customers as at the time order was placed and when the meal actually arrived was what was dealt with under this section. The results of this analysis is discussed below;

Table 6. Wait Time Experienced and Acceptable after Placing my Order.

\begin{tabular}{lll}
\hline & Frequency & Percent \\
\hline Wait time experienced & & \\
5 minutes or less & 13 & 26.5 \\
6-10 minutes & 12 & 24.5 \\
$11-15$ minutes & 9 & 18.4 \\
$16-20$ minutes & 6 & 12.2 \\
$21-25$ minutes & 4 & 8.2 \\
26 and above minutes & 5 & 10.2 \\
\hline
\end{tabular}




\begin{tabular}{lll}
\hline & Frequency & Percent \\
\hline Acceptable time to wait & & \\
5 minutes or less & 16 & 32.0 \\
6-10 minutes & 18 & 36.3 \\
11-15 minutes & 9 & 19.1 \\
16-10 minutes & 2 & 4.3 \\
$21-25$ minutes & 2 & 4.3 \\
\hline
\end{tabular}

Table 6 above compare the actual and expected waiting times of customers to a restaurant after they have placed an order. It is observed that the actual and expected waiting times vary with average actual and expected values being 13.60 and 10.32 respectively as shown in the table 4.1 below. The table 7 below displays results of further statistics that help us conclude as to whether there exists significant difference between the actual and expected average waiting time.

Table 7. Comparing the Average Time Experienced and Wait Time Expected After Placing my Order

\begin{tabular}{lll}
\hline & $\begin{array}{l}\text { Wait time } \\
\text { experienced }\end{array}$ & $\begin{array}{l}\text { Wait time } \\
\text { expected }\end{array}$ \\
\hline Mean & 13.60 & 10.32 \\
Variance & 54.73 & 27.61 \\
Observations & 50.00 & 47.00 \\
Hypothesized Mean Difference & 0.00 & \\
Df & 89.00 & \\
t Stat & 2.53 & \\
P $(\mathrm{T}<=\mathrm{t})$ one-tail & 0.01 & \\
t Critical one-tail & 1.66 & \\
\hline
\end{tabular}

The results in the table support the non-acceptance of the null hypothesis that seeks to suggest there is no significant difference between the average expected and actual waiting times of customers after they have placed an order. The PValue of 0.01 is less than 0.05 providing us enough evidence at the $95 \%$ confidence level to reject the null hypothesis and aids us in confidently stating that the average actual waiting time is far more than the customers expect after they have placed an order. Customers are hence not satisfied with the time they spend waiting after placing an order.

Waiting time after completing a meal

After a meal is completed, how long does it take to get the payment ticket in order to complete the eating process? Both expected and actual data of customers' perception and experience was taken and analyzed and the results discussed below;

Table 8. Wait Time Experienced and Acceptable after Completing Meal.

\begin{tabular}{lll}
\hline & Frequency & Percent \\
\hline Wait time experienced & & \\
5 minutes or less & 12 & 25.5 \\
6-10 minutes & 20 & 42.6 \\
11-15 minutes & 6 & 12.8 \\
16-20 minutes & 3 & 6.4 \\
21-25 minutes & 3 & 6.4 \\
26 and above minutes & 3 & 6.4 \\
Acceptable time to wait & & \\
5 minutes or less & 21 & 44.7 \\
6-10 minutes & 17 & 36.2 \\
11-15 minutes & 3 & 6.4 \\
16-10 minutes & 3 & 6.4 \\
21-25 minutes & 3 & 6.4 \\
\hline
\end{tabular}

Table 8 also juxtaposes actual and expected waiting times of customers after they are done eating. It is observed that, only about $19 \%$ of the times would customers want to spend more than ten (10) minutes in the restaurant after they are done eating. It is also the case that customers would only about $19 \%$ of the times spend ten or more minutes in the restaurant after completing a meal. However, the average expected waiting time and actual waiting time still vary when a close look is taken at time classification below ten minutes hence it is important to confidently decide whether there is a difference between the average of the actual and expected waiting times of the customers after they have completed a meal. Table 5.1 below helps us to do this conclusion.

Table 9. Significant test of expected and actual average waiting times after completing a meal.

\begin{tabular}{lll}
\hline & $\begin{array}{l}\text { Wait time } \\
\text { experienced }\end{array}$ & $\begin{array}{l}\text { Wait time } \\
\text { expected }\end{array}$ \\
\hline Mean & 11.94 & 9.69 \\
Variance & 42.83 & 33.41 \\
Observations & 48 & 48 \\
Hypothesized Mean Difference & 0 & \\
df & 93 & \\
t Stat & 1.79 & \\
$\mathrm{P}(\mathrm{T}<=$ t) one-tail & 0.04 & \\
t Critical one-tail & 1.66 & \\
$\mathrm{P}(\mathrm{T}<=\mathrm{t})$ two-tail & 0.08 & \\
t Critical two-tail & 1.99 & \\
\hline
\end{tabular}

The table 9 again supports the rejection of the null hypothesis that there is no significant difference between the average actual and expected waiting times of customers after completing a meal at the restaurant. The P-Value of 0.04 is less than 0.04 indicating that we have strong evidence to suggest that there are significant differences between the averages of the actual and expected waiting times of customers after completing a meal.

Discussions of waiting times

From the findings, it can be seen that under each stage, the time customers spend in wait is always longer than their expectation of how long they should wait. This can result in dissatisfaction with the service provider as stated by [9] who opined that even though waiting cost may be considered low cost, its overall effect could be catastrophic ending up in high cost. Comparatively, the restaurants in this study cannot be seen to have lower waiting times as compared to what [8] proposed. The total actual average waiting time observed is 43.46 (sum of all the actual average waiting times under all the sections). [8] indicated that a waiting time is unacceptable if it hits the regions of 47.91 minutes. Customers' dissatisfaction therefore is justified as total waiting time is too high. [10] actually pegged acceptable waiting time at 160 seconds which is a long way from what currently exists in this industry. By this level of variance, the words of [11] could be anticipated as Taylor indicated that perceived unimaginable service delay can result in the feeling of anger among customers. Consequently, the overall satisfaction of the customer regarding the service being provided can also be influenced as discussed by [7]. A reflection of the effect of 
this long waiting times is likely to be seen in the way customers would rate their satisfaction with the behavioral aspect of the process measured.

Assessment of Restaurant Server's Behaviors

In order to assess the behaviors restaurant servers are likely to engage in, twenty-nine (29) different and independent behavioral items were identified and presented to customers to rate. These items were rated on a five point likert scale with the least rate being "Not at all satisfied" and coded 1 and the highest rate being "Extremely satisfied" and coded 5 . The results are displayed and discussed below.

Table 10. Frequency distribution of restaurant server's behaviors.

\begin{tabular}{|c|c|c|c|c|c|c|}
\hline Behavior & NS & SS & $\mathbf{S}$ & VS & ES & Mode \\
\hline V1. The server smiles when greeting the customer & 1 & 6 & 16 & 20 & 6 & VS \\
\hline V2. The server accommodates special requests of the customer & 2 & 9 & 27 & 8 & 4 & $\mathrm{~S}$ \\
\hline V3. The server thoroughly explains menu & 2 & 8 & 26 & 9 & 5 & $\mathrm{~S}$ \\
\hline V4. The server makes direct eye contact with the customer & 3 & 8 & 19 & 15 & 5 & $\mathrm{~S}$ \\
\hline V5. The server's nails and hands are well manicured & 3 & 6 & 26 & 8 & 6 & $\mathrm{~S}$ \\
\hline V6. The server provides for the customer's special needs when asked & 1 & 8 & 18 & 15 & 7 & $\mathrm{~S}$ \\
\hline V7. The server allows the customer opportunity for privacy & 2 & 7 & 14 & 19 & 8 & VS \\
\hline V9. The server's manners makes the customer feel comfortable & 2 & 6 & 26 & 10 & 6 & $\mathrm{~S}$ \\
\hline V10. The server's clothes are well maintained & 2 & 2 & 17 & 19 & 10 & VS \\
\hline V11. The server explains how menu items are prepared or cooked & 7 & 14 & 18 & 9 & 2 & $\mathrm{~S}$ \\
\hline V12. The server behaves in a formal manner & 3 & 10 & 20 & 12 & 5 & $\mathrm{~S}$ \\
\hline V13. The server delivers menu items to the table in proper sequence & 4 & 8 & 22 & 11 & 4 & $\mathrm{~S}$ \\
\hline V14. The sever replenishes beverages frequently, without being asked & 6 & 16 & 20 & 6 & 2 & $\mathrm{~S}$ \\
\hline V15. The server is sensitive to the customer's mood & 5 & 17 & 18 & 4 & 6 & $\mathrm{~S}$ \\
\hline V16. The server attends to special customer needs without being asked & 2 & 13 & 25 & 8 & 2 & $\mathrm{~S}$ \\
\hline V18. The server clarifies any uncertainty about the food items listed on the menu & 2 & 7 & 27 & 10 & 4 & $\mathrm{~S}$ \\
\hline V19. The server changes dishes when necessary & 1 & 12 & 21 & 6 & 2 & $\mathrm{~S}$ \\
\hline V20. The server knows when the customer doesn't want to be bothered & 8 & 13 & 13 & 14 & 2 & VS \\
\hline V21. The server doesn't interrupt if customers are conversing among themselves & 3 & 7 & 14 & 18 & 8 & VS \\
\hline V22. When customers explain they have little time to eat, the server speeds up the pace & 5 & 4 & 31 & 5 & 5 & $\mathrm{~S}$ \\
\hline V23. The server is prompt in removing dishes after the customer has completed a course & 2 & 12 & 19 & 12 & 3 & $\mathrm{~S}$ \\
\hline V24. The server assists the customer in deciding what to order & 2 & 3 & 27 & 11 & 6 & $\mathrm{~S}$ \\
\hline V25. The server stops by the table frequently to check for additional customer needs & 3 & 14 & 13 & 10 & 9 & SS \\
\hline V26. The server's hair is neat and well groomed & 1 & 4 & 21 & 16 & 7 & $\mathrm{~S}$ \\
\hline V27. The server provides friendly conversation & 4 & 3 & 26 & 10 & 6 & $\mathrm{~S}$ \\
\hline V28. The server avoids touching the surface of eating utensils & 2 & 9 & 13 & 15 & 10 & VS \\
\hline V29. The server looks attractive & 6 & 5 & 16 & 12 & 10 & $\mathrm{~S}$ \\
\hline
\end{tabular}

Table 10 above displayed the results of the behaviors of restaurant servers that are exhibited on daily basis and the level of satisfaction attached to each. It is observed that customers are satisfied with majority of these behaviors with few of them being rated as very satisfied. None of the behaviors measured cause high level of dissatisfaction among customers as can be seen in the tables above.

Table 11. Descriptive Statistics of restaurant server's behaviors.

\begin{tabular}{|c|c|c|c|c|c|c|c|}
\hline \multirow{2}{*}{ Behaviors } & \multirow{2}{*}{ Mean } & \multirow{2}{*}{ Std. Deviation } & \multirow{2}{*}{ Minimum } & \multirow{2}{*}{ Maximum } & \multicolumn{3}{|c|}{ Percentiles } \\
\hline & & & & & 25th & 50th (Median) & 75th \\
\hline V1 & 3.54 & .854 & 2 & 5 & 3.00 & 4.00 & 4.00 \\
\hline $\mathrm{V} 2$ & 3.00 & .858 & 1 & 5 & 3.00 & 3.00 & 3.00 \\
\hline V3 & 3.10 & .882 & 1 & 5 & 3.00 & 3.00 & 4.00 \\
\hline V4 & 3.03 & .959 & 1 & 5 & 2.00 & 3.00 & 4.00 \\
\hline V5 & 3.15 & .904 & 1 & 5 & 3.00 & 3.00 & 4.00 \\
\hline V6 & 3.38 & .935 & 2 & 5 & 3.00 & 3.00 & 4.00 \\
\hline V7 & 3.62 & .935 & 1 & 5 & 3.00 & 4.00 & 4.00 \\
\hline V8 & 3.15 & .745 & 2 & 5 & 3.00 & 3.00 & 4.00 \\
\hline V9 & 3.23 & .959 & 1 & 5 & 3.00 & 3.00 & 4.00 \\
\hline V10 & 3.49 & .970 & 1 & 5 & 3.00 & 4.00 & 4.00 \\
\hline V11 & 2.62 & 1.067 & 1 & 5 & 2.00 & 3.00 & 3.00 \\
\hline V12 & 3.03 & .986 & 1 & 5 & 2.00 & 3.00 & 4.00 \\
\hline V13 & 3.08 & 1.061 & 1 & 5 & 3.00 & 3.00 & 4.00 \\
\hline V14 & 2.54 & .913 & 1 & 5 & 2.00 & 3.00 & 3.00 \\
\hline V15 & 2.67 & 1.060 & 1 & 5 & 2.00 & 3.00 & 3.00 \\
\hline V16 & 2.82 & .885 & 1 & 5 & 2.00 & 3.00 & 3.00 \\
\hline V17 & 2.90 & 1.119 & 1 & 5 & 2.00 & 3.00 & 4.00 \\
\hline V18 & 3.05 & .887 & 1 & 5 & 3.00 & 3.00 & 4.00 \\
\hline
\end{tabular}




\begin{tabular}{|c|c|c|c|c|c|c|c|}
\hline \multirow{2}{*}{ Behaviors } & \multirow{2}{*}{ Mean } & \multirow{2}{*}{ Std. Deviation } & \multirow{2}{*}{ Minimum } & \multirow{2}{*}{ Maximum } & \multicolumn{3}{|c|}{ Percentiles } \\
\hline & & & & & 25th & 50th (Median) & 75th \\
\hline V19 & 2.97 & .843 & 1 & 5 & 2.00 & 3.00 & 3.00 \\
\hline V20 & 2.74 & 1.093 & 1 & 5 & 2.00 & 3.00 & 4.00 \\
\hline $\mathrm{V} 21$ & 3.51 & 1.048 & 1 & 5 & 3.00 & 4.00 & 4.00 \\
\hline V22 & 2.97 & 1.013 & 1 & 5 & 3.00 & 3.00 & 3.00 \\
\hline V23 & 2.97 & .959 & 1 & 5 & 2.00 & 3.00 & 4.00 \\
\hline V24 & 3.31 & .950 & 1 & 5 & 3.00 & 3.00 & 4.00 \\
\hline V26 & 3.38 & .877 & 1 & 5 & 3.00 & 3.00 & 4.00 \\
\hline V27 & 3.10 & .940 & 1 & 5 & 3.00 & 3.00 & 4.00 \\
\hline V28 & 3.31 & 1.151 & 1 & 5 & 2.00 & 3.00 & 4.00 \\
\hline V29 & 3.26 & 1.229 & 1 & 5 & 3.00 & 3.00 & 4.00 \\
\hline
\end{tabular}

The descriptive statistics table above displays the mean ranks of the variables measured with their corresponding standard deviations and percentiles. A critical study of the results shows a validation of the mean ranks by the median values as almost all of them are approximately same. The implication is that customers are generally satisfied with the behaviors of restaurant servers. However, the varying mean ranks of the responses indicate that the items might not all be ranked same and that some have higher satisfaction than others. Further test was performed to substantiate this claim and the results displayed below;
Table 12. Significant test for all behavior items.

\begin{tabular}{ll}
\hline $\mathbf{N}$ & $\mathbf{3 9}$ \\
\hline Chi-Square & 104.277 \\
df & 28 \\
Asymp. Sig. & .0001 \\
\hline
\end{tabular}

The P-Value of 0.0001 is less than 0.05 supporting the assertion that all the variables do not have the same ranking hence the need to identify the groupings within all the variables with equal ranking. Three major clusters were identified after performing further tests. The following table display the results:

Table 13. Grouping of restaurant server's behavior.

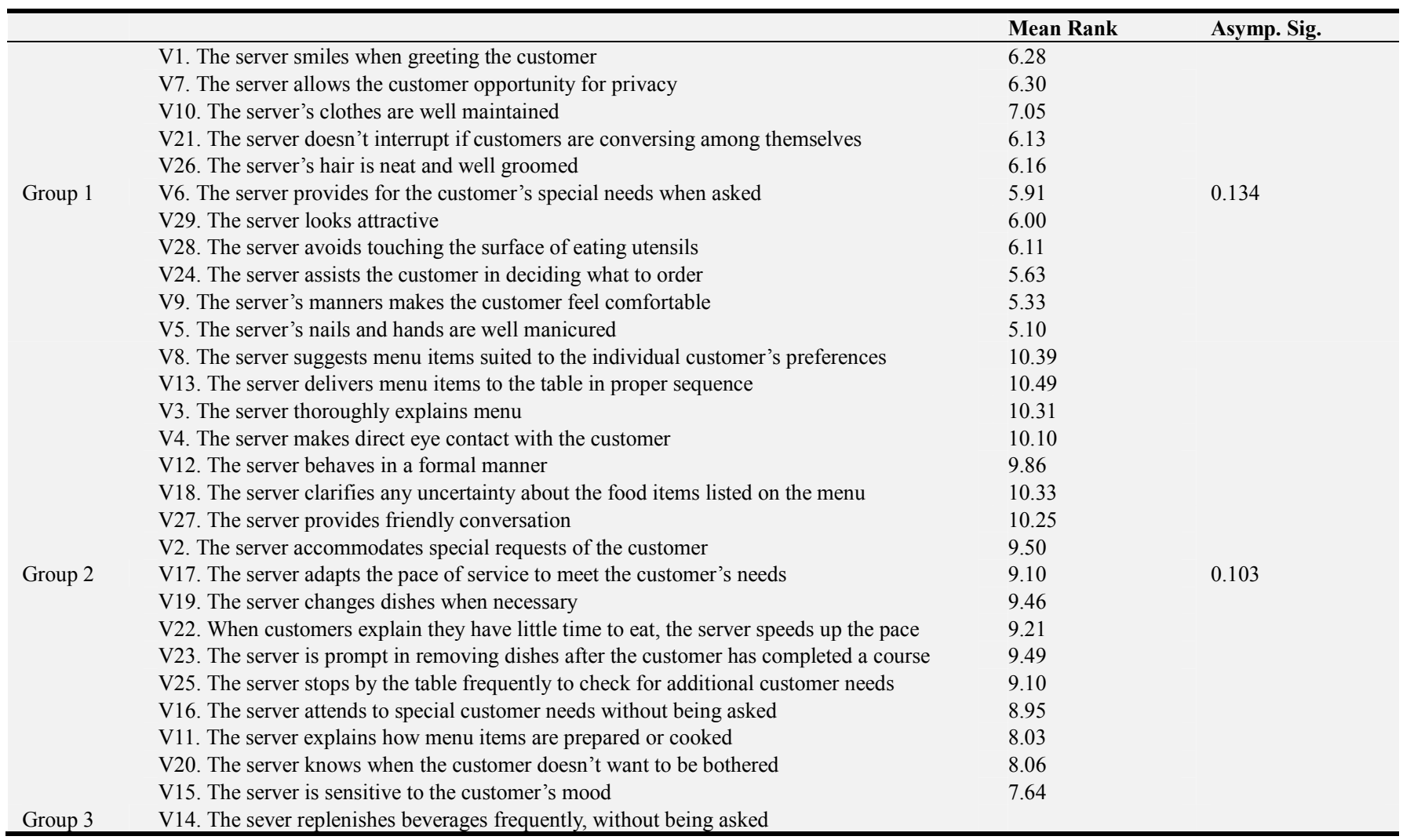

The information in table 13 is the re-grouping of the restaurant servers' behaviors according to their ranks as obtained. Three different groups were obtained for which within each group, the significant values indicate no difference in their mean ranks. Group one which comprised eleven (11) server behaviors can be identified more with the personality traits/attributes of the server. These are characteristics of the server which are personal to him or her 
and has to do with the individual's ability to make a customer feel at home whiles at the restaurant. These are the highest rated attributes of the server and are seen to be more appreciated by customers hence their higher ranking.

Group two (2) comprise seventeen (17) server attribute/behaviors which are ranked second highest with the asymptotic significant value indicating no difference within their mean ranks. The implication is that; we can confidently say they are all ranked equal. These group of attributes are seen to be more about the work/job hence it is being referred to as job related attributes of the server. They are more focused on giving the customer a professional touch during service delivery through attributes like the prompt changing of dishes, being sensitive to customer mood, thoroughly explaining to the server everything on request etc. these factors were also appreciated by the customers of the restaurants but their level of appreciation is a little lower than that of group one (personality traits/attributes of the server).

Group three (3) comprise of only one standalone item which is the "replenishment of beverages quickly without being asked. This item is the item with the least rank. This might probably be due to the specific nature of the item. It can be termed "the request attribute".

From the findings, satisfaction with the group 2 items being called the job related attributes/items have lower levels of satisfaction. All the variables that are more related to the restaurant is seen to receive lower ratings than the personality trait behaviors. This may be due to the spillover effects of the excessive waiting times as opined by [5]; [12]. [11] also indicated that delays in service of any kind in the hospitality industry could lead to low ratings by dissatisfied customers in the final evaluation of service quality or a rapid decline in the revenue. The third group is a greater evidence to this as customers indicated that it takes absolutely too long for the replenishment of their beverages during the service period.

The results were again tested on the gender scale to see if gender influenced the results. It was identified that for all the twenty-nine (29) variables measured, none of them was gender sensitive/influenced. This means both males and females are of same opinion and that males do not share a different opinion regarding any of the items as compared to females.

\section{Conclusion and Recommendation}

Average waiting time under all the sub sections measured exceeds the average waiting time customers actually want to do. This is not good for customers as they want a cut down on the amount of time spent waiting from the period of entering the restaurant to the point of exiting. It is confidently concluded that customers are not satisfied with the long waiting times spent in the restaurant. This could affect total satisfaction of the customers. Also, server behaviors are good with the personality traits of the servers being ranked highest followed by the job related attributes. Request related attributes were the least ranked

It is thus recommended that management and employees should work hard at reducing the waiting times at each level of the service process since customers are dissatisfied with the excessive waiting times. Most customers would prefer not spending more than five minutes at each stage of the service process hence management should seriously consider activities that will help reduce the waiting time. Furthermore, management should equally put in place some measures that will prevent customers from feeling bored during the period of waiting. Activities that will engage the customers should be introduced. This can replace the feeling of anger that is likely to rise when customers wait too long. Finally, the job related attributes and request related attributes of the servers especially should be worked on to improve their rating. Currently, the level of satisfaction with such attributes is not as good as the personality traits of the servers.

\section{References}

[1] Kaplan, R. S., \& Norton, D. P. (2001). Transforming the balanced scorecard from performance measurement to strategic management: Part I. Accounting horizons, 15(1), 87-104.

[2] Alsumait, K. (2015). Guests' Waiting Experience at Hotels: Evidence from Saudi Arabia. Saudi Arabia.

[3] Qureshi, M. I., Bhatti, M., Khan, A., \& Zaman, K. (2014). Measuring queuing system and time standards: A case study of student affairs in universities. African Journal of Business Management, 8(2), 80 .

[4] Kandemir-Caues, C., \& Cauas, L. (2007). An Application of Queuing Theory to the Relationship between Insulin Level and Number of Insulin Receptors. Turkish Journal of Biochemistry, 32 (1): 32-38.

[5] Bielen, F., \& Demoulin, N. (2007). Waiting time influence on the satisfaction-loyalty relationship in services. Managing Service Quality. An International Journal, 17(2), 174-193.

[6] Zeithaml, V., \& Bitner, J. (2002). Services Marketing: Integrating Customer Focus across the Firm, 3rd ed., New York, NY: McGraw-Hill Higher Education.

[7] Pruyn, A., \& Smidts, A. (1998). "Effects of waiting on the satisfaction with the service: beyond objective time measures". International Journal of Research in Marketing, Vol. 15 No. 4, pp. 321-34.

[8] Hwang, J., \& Lambert, C. U. (2006). Customers' identification of acceptable waiting times in a multi-stage restaurant system. Journal of Foodservice Business Research, 8(1), 3-16.

[9] Cameron, M. A., Baker, J., Peterson, M., \& Braunsberger, K. (2003). The effects of music, wait-length evaluation, and mood on a low-cost wait experience. Journal of Business Research, 56(6), 421-430.

[10] Kokkinou, A., \& Cranage, D. A. (2013). Using self-service technology to reduce customer waiting times. International Journal of Hospitality Management, 33, 435-445.

[11] Taylor, S. (1994). Waiting for service: the relationship between delays and evaluations of service. The journal of marketing, 56-69.

[12] Maister, D. (1985). The one-firm firm. Sloan Management Review, 27(1), 3-13. 